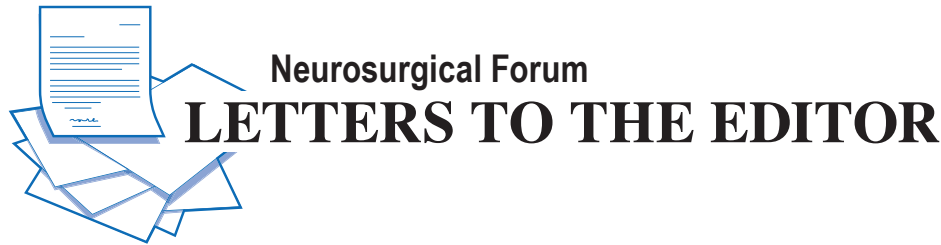

\section{Influence of age on survival outcomes in patients with spinal chordoma}

TO THE EDITOR: We read with great interest the recent article by Gokaslan et al. ${ }^{3}$ (Gokaslan ZL, Zadnik PL, Sciubba DM, et al: Mobile spine chordoma: results of 166 patients from the AOSpine Knowledge Forum Tumor database. J Neurosurg Spine 24:644-651, April 2016). The authors performed a retrospective multicenter cohort analysis of prognostic factors in mobile spine chordoma after resection in 166 patients. They found on multivariate analysis that Enneking-inappropriate resection was significantly associated with an increased risk of local recurrence in the patients.

We commend the authors for performing this interesting study as their helpful results will be useful in making balanced treatment decisions to prolong patient survival. However, we noted that the authors did not find patient age to be an independent predictor, which contradicts the results from previous studies. ${ }^{7,8,10}$ Furthermore, although an increasing number of studies have investigated the influence of age on spinal chordoma prognosis, the results are still inconclusive or controversial. Therefore, we aimed to further examine the prognostic role of age in spinal chordoma by performing a systematic review and to grade the evidence according to the quality of included studies. We also attempted to establish pooled estimates of the effect of age on the survival of spinal chordoma patients by performing a meta-analysis.

We searched the MEDLINE and Embase databases to identify eligible English-language studies from database inception to September 9, 2016. We included only those studies that specifically evaluated age as a factor predicting survival in spinal chordoma patients. Methodological quality for study inclusion was assessed according to the criteria previously described., ${ }^{1,5,11}$ Studies without sufficient detailed data for statistical pooling were excluded. Level of evidence was determined according to the criteria proposed by Harbour and Miller. ${ }^{4}$

A total of 11 papers met the initial methodological criteria and were thus included. ${ }^{2,3,6-10,12-15}$ Characteristics of the included studies are shown in Table 1. All studies were retrospective, and most (9/11) provided Level 2++ evidence. Sample size ranged from 36 to 167 patients with spinal chordoma. Most studies (10/11) only evaluated the prognostic role of age on survivorship to local recurrence or death. ${ }^{2,6-10,12-15}$ Although most studies (8/11) found that patient age had no significant predictive value, , $3,6,9,10,12,13,15^{-15}$ 3 studies showed significant prognostic implications for age on the overall survival (OS) of patients. ${ }^{7,8,10}$ Five studies evaluated age as a factor of OS in multivariate analyses by regarding it as a continuous variable,,$^{3,7-10}$ and pooled analysis showed that increasing age was associated with an increased risk of death (HR 1.03, 95\% CI 1.02-1.05, p $<0.0001, \mathrm{I}^{2}=52 \%$, p for heterogeneity $=0.08$; Fig. 1). Although 5 studies evaluated age as a factor of local relapsefree survival with the same cutoff point, ${ }^{2,12-15} 4$ of them shared exactly the overlapped patient data. ${ }^{12-15}$ Therefore, we did not pool the results in order to allow the credibility and accuracy of the outcomes.

According to the evidence available, we cannot derive valid conclusions regarding the prognostic role of patient age in spinal chordoma. The difference in categorization

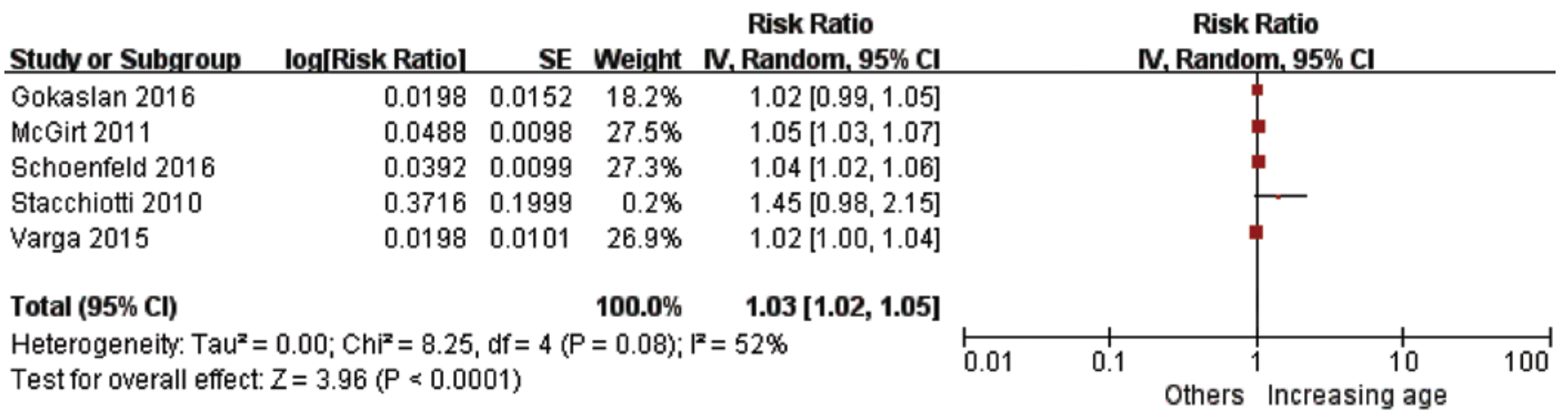




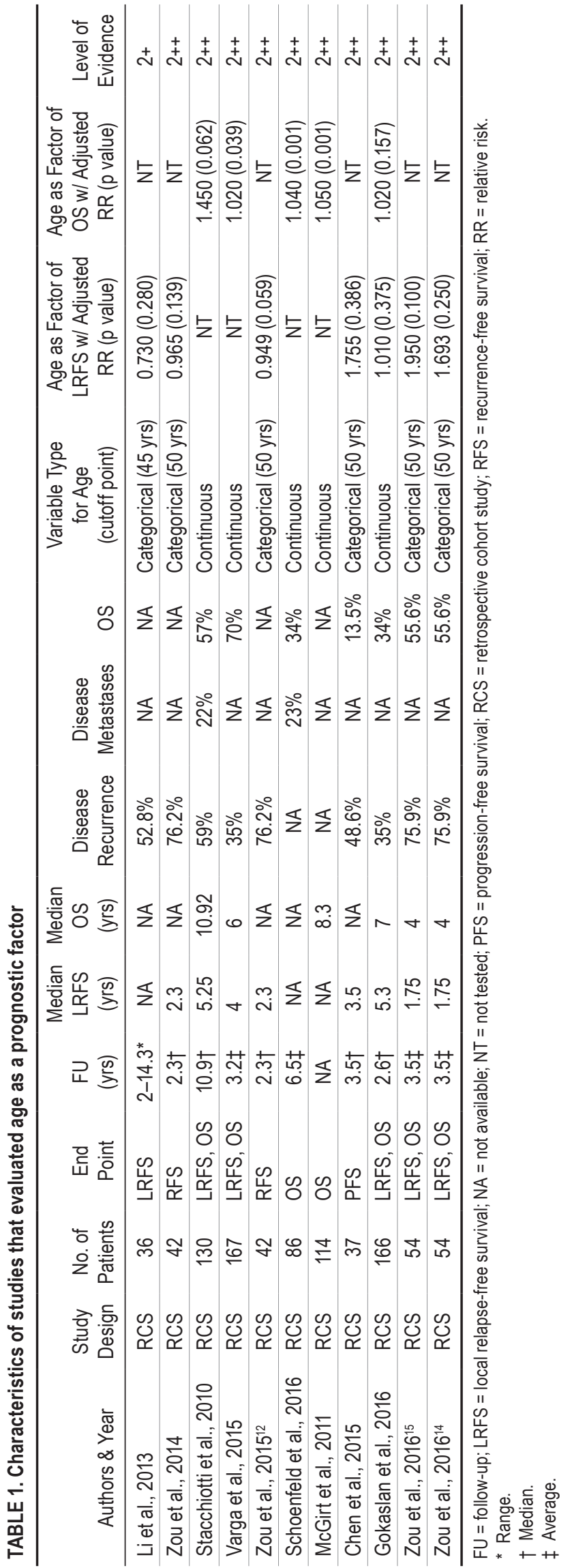

for age between papers and the heterogeneity of the included studies render the pooled results less reliable. Subsequent methodologically high-quality studies with more uniform study design and data reporting are needed to further define the role of age in spinal chordoma prognosis.

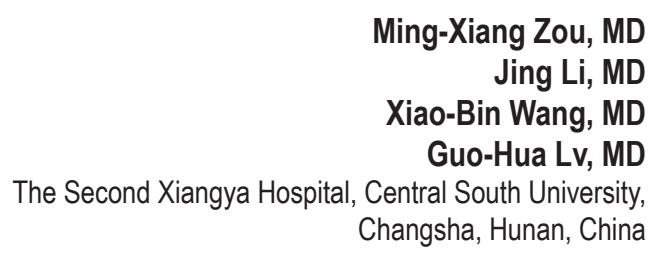

\section{References}

1. Bramer JA, van Linge JH, Grimer RJ, Scholten RJ: Prognostic factors in localized extremity osteosarcoma: a systematic review. Eur J Surg Oncol 35:1030-1036, 2009

2. Chen H, Zhang K, Wu G, Song D, Chen K, Yang H: Low expression of PHLPP1 in sacral chordoma and its association with poor prognosis. Int J Clin Exp Pathol 8:14741-14748, 2015

3. Gokaslan ZL, Zadnik PL, Sciubba DM, Germscheid N, Goodwin CR, Wolinsky JP, et al: Mobile spine chordoma: results of 166 patients from the AOSpine Knowledge Forum Tumor database. J Neurosurg Spine 24:644-651, 2016

4. Harbour R, Miller J: A new system for grading recommendations in evidence based guidelines. BMJ 323:334-336, 2001

5. Hayden JA, Côté P, Bombardier C: Evaluation of the quality of prognosis studies in systematic reviews. Ann Intern Med 144:427-437, 2006

6. Li X, Wang S, Chen Y, Liu G, Yang X: Overexpression of CD40 in sacral chordomas and its correlation with low tumor recurrence. Onkologie 36:567-571, 2013

7. McGirt MJ, Gokaslan ZL, Chaichana KL: Preoperative grading scale to predict survival in patients undergoing resection of malignant primary osseous spinal neoplasms. Spine J 11:190-196, 2011

8. Schoenfeld AJ, Wang X, Wang Y, Hornicek FJ, Nielsen GP, Duan Z, et al: CSPG4 as a prognostic biomarker in chordoma. Spine J 16:722-727, 2016

9. Stacchiotti S, Casali PG, Lo Vullo S, Mariani L, Palassini E, Mercuri M, et al: Chordoma of the mobile spine and sacrum: a retrospective analysis of a series of patients surgically treated at two referral centers. Ann Surg Oncol 17:211-219, 2010

10. Varga PP, Szövérfi Z, Fisher CG, Boriani S, Gokaslan ZL, Dekutoski MB, et al: Surgical treatment of sacral chordoma: prognostic variables for local recurrence and overall survival. Eur Spine J 24:1092-1101, 2015

11. Zou MX, Huang W, Wang XB, Li J, Lv GH, Deng YW: Prognostic factors in spinal chordoma: a systematic review. Clin Neurol Neurosurg 139:110-118, 2015

12. Zou MX, Huang W, Wang XB, Li J, Lv GH, Wang B, et al: Reduced expression of miRNA-1237-3p associated with poor survival of spinal chordoma patients. Eur Spine J 24:17381746,2015

13. Zou MX, Huang W, Wang XB, Lv GH, Li J, Deng YW: Identification of miR-140-3p as a marker associated with poor prognosis in spinal chordoma. Int J Clin Exp Pathol 7:4877-4885, 2014

14. Zou MX, Lv GH, Li J, She XL, Jiang Y: Upregulated human telomerase reverse transcriptase (hTERT) expression is associated with spinal chordoma growth, invasion and poor prognosis. Am J Transl Res 8:516-529, 2016

15. Zou MX, Peng AB, Lv GH, Wang XB, Li J, She XL, et al: Expression of programmed death-1 ligand (PD-L1) in tumor- 
infiltrating lymphocytes is associated with favorable spinal chordoma prognosis. Am J Transl Res 8:3274-3287, 2016

\section{Disclosures}

The authors report no conflict of interest.

\section{Response}

We appreciate the letter from Zou et al., who should be commended for their effort and rigor in actually conducting a review of the literature in their response. Specifically, they first noted that our study did not find a predictive association between increasing patient age and worse survival following resection of mobile spine chordomas. They then conducted a literature review to provide evidence for or against such an association.

Interestingly, although they found that some prior studies show that increasing age is associated with worse survival following mobile spine chordoma resection, they also found multiple studies that show no association, similar to our study. As a result, they concluded that the body of current literature does not support an association between age and survival, and thus that more research should be done on the subject.

With regard to our original study, we sought to retrospectively evaluate prospectively acquired data on patients undergoing surgery for mobile spine chordomas from multiple centers in multiple nations. Given the rarity of these tumors in general and the limited long-term data following such surgeries, a multicenter study was performed to generate larger numbers. Not surprisingly, we found that local control following surgery is associated with the extent of oncological resection in the original surgery. However, we did not find an association between age and survival. Although Varga et al., in using a very similar methodology employed through the participating centers of the AOSpine Knowledge Forum Tumor network, did find an association between age and worsening prognosis following resection of sacral chordomas, it is unclear why such an association does not exist for mobile spine chordomas in our study. ${ }^{1}$

It is important to note that the clinical behavior of clival, mobile spine, and sacral chordomas are indeed different, suggesting an underlying difference in pathophysiology among tumors in these distinct locations. As more work is done to elucidate the mechanisms by which chordomas appear, grow, recur, and metastasize, it is likely that molecular factors will soon be identified as the most accurate predictors of survival following the diagnosis of spinal chordoma. Such molecular studies, ${ }^{2-6}$ which have been provided in many forms by Zou and colleagues, will undoubtedly improve our clinical management of patients with these very challenging lesions.

Daniel M. Sciubba, MD

Johns Hopkins University, Baltimore, MD

\section{References}

1. Varga PP, Szövérfi Z, Fisher CG, Boriani S, Gokaslan ZL, Dekutoski MB, et al: Surgical treatment of sacral chordoma: prognostic variables for local recurrence and overall survival. Eur Spine J 24:1092-1101, 2015

2. Zou MX, Huang W, Wang XB, Li J, Lv GH, Deng YW: Prognostic factors in spinal chordoma: A systematic review. Clin Neurol Neurosurg 139:110-118, 2015

3. Zou MX, Huang W, Wang XB, Li J, Lv GH, Wang B, et al: Reduced expression of miRNA-1237-3p associated with poor survival of spinal chordoma patients. Eur Spine J 24:17381746,2015

4. Zou MX, Huang W, Wang XB, Lv GH, Li J, Deng YW: Identification of miR-140-3p as a marker associated with poor prognosis in spinal chordoma. Int J Clin Exp Pathol 7:4877-4885, 2014

5. Zou MX, Lv GH, Li J, She XL, Jiang Y: Upregulated human telomerase reverse transcriptase (hTERT) expression is associated with spinal chordoma growth, invasion and poor prognosis. Am J Transl Res 8:516-529, 2016

6. Zou MX, Peng AB, Lv GH, Wang XB, Li J, She XL, et al: Expression of programmed death-1 ligand (PD-L1) in tumorinfiltrating lymphocytes is associated with favorable spinal chordoma prognosis. Am J Transl Res 8:3274-3287, 2016

\section{INCLUDE WHEN CITING}

Published online February 24, 2017; DOI: 10.3171/2016.9.SPINE161083.

CAANS, 2017 